\title{
A two-step model for integrating creative teaching in higher education
}

\section{Nathalie Sheridan}

University of Glasgow, UK

\section{Abstract}

This paper provides examples of practice demonstrating some underlying principles of translating creative and active pedagogies from school into a higher education context, using a simple two-step model and the concept of creative learning and teaching (Jeffrey, 2006). Since working in higher education, I sought to translate the principles of creative learning and teaching (Jeffrey, 2006) into my praxis.

This exercise became particularly prudent when moving into academic development, trying to convey the successful principles underlying my pedagogy to colleagues on the Masters in Academic Practice. The paper will discuss a two-step model I developed: de-contextualizing and then re-contextualizing sometimes complex and intangible learning content to make it more accessible for learners. This will be exemplified by two teaching cases and evidenced with data I collected during my own Postgraduate Certificate in Learning and Teaching in Higher Education, demonstrating how the approach improved student performance and the overall quality of their academic work. These principles could be easily translated into different disciplinary contexts, with different groups of students.

Keywords: creative learning and teaching; active learning; student transition; student learning development; academic development. 


\section{Background}

Learning development sits in a contested space in terms of its location within 'remedial' policies of some institutions; but it can embody the very best of emancipatory practice (Sinfield, et al., 2011, p. 61).

A reoccurring issue working in learning development is to encourage students to engage with learning opportunities that are above and beyond the mere subject disciplines, instead of taking a reductionist performative approach to their learner journey (Biggs and Tang, 2011). University is a transitional space, an 'in-culture' (Sheridan, 2011) that students have to learn to negotiate and understand; a space necessitating new cultural competences. Transitioning into university as a first-year student, as a return to study master's student, or as an international student, thus becomes a complex and challenging notion.

For students, the move to university is a personal investment of the cultural capital accrued through school and college education. It is also a significant social displacement, which may be intensified where the student is mature, is the first in their family to attend university, or is from an ethnic group under-represented in the university population (Briggs et al., 2012, p. 1-2).

Briggs et al. (2012) describe transition into university as cultural displacement for students, particularly students from underrepresented groups. Universities are not only transitional spaces for students to 'become' professionals, educated, and attractive to the job-market (Glasgow Caledonian University, 2014), but also for university teachers whose professional identities are of perpetual becoming (Ashwin, et al., 2015; Kidd, 2015).

Whilst both educators and students are engaged in these identity negotiations, the abovementioned cultural displacement can be particularly acute for vulnerable student groups, such as first-generation students. Mckendry et al. (2013) observe that these students make disproportionate use of learning development offers, which does not only aid their academic achievements but can foster a sense of belonging and agency (Stebleton, Soria and Huesman, 2014; Richards et al., 2017). However, not only for vulnerable students but 
for all students transitioning into university, learning development sessions can help the integration of the learners into the university context (Lee, 2001). To enable learners to take agency of their learner journeys I introduced principles of creative learning and teaching (Jeffrey, 2006) into my higher education pedagogy, with the aim to enable the students to take ownership and control of their academic development. In conjunction with this, I decided to focus my own PGCert course work on this translation of creative pedagogies into higher education.

If the students do not understand the relevance of academic development sessions for their learning, they might not engage in these (Sheridan, 2011). To create this relevance, I intended to build a bridge for the students between cultural competences for academia and their subject disciplines. The principle of my approach is to de-contextualize the learning-aim from the purely academic skills into a meaningful experience the students could engage with, and negotiate positive learner-identities, subsequently recontextualizing it into the academic context.

\section{Figure 1. Two-step model}
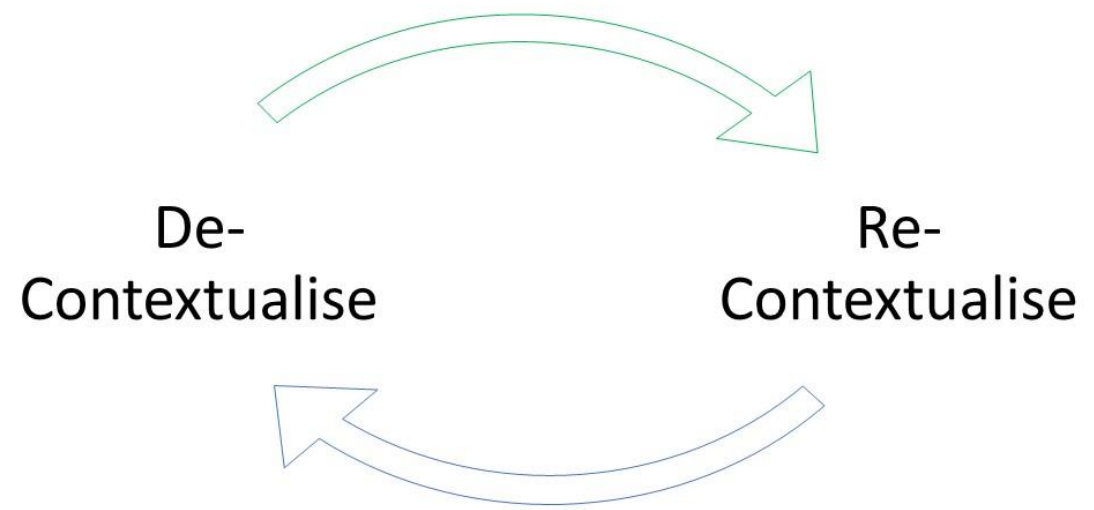

To elaborate this principle in more detail in university degrees, we often have to convey complex concepts, theories, or principles to our students. Approaching teaching from the theorizing viewpoint can make these concepts more inaccessible. So, breaking these concepts down into the underlying principles, and identifying parameters, descriptors, elements of these principles or concepts, and translating these into something tangible 
(Kolb, 2015) or something that students can get hold of and can experiment with, helps to make these principles and concepts more accessible to the students. This is where the 'de-contextualizing' of the model takes hold. It creates triggered situational interest, which enhances engagement during class, and has the potential to be carried forward by the learner beyond the classroom setting (Symonds et al., 2019).

I have established earlier that learning is in the dichotomy of the sense making process between socially mediated-extrinsic, and individual-intrinsic, activity (Sheridan, 2011). Supporting students in developing their metacognitive skills, and understanding how academic development sessions can enhance their learning, and performance, can enhance their engagement (Symonds et al., 2019). With the caveat that the topic of engagement and motivation is more complex than that (for example Zepke, 2017; Kahu, Picton and Nelson, 2019; Symonds et al., 2019) my research has indicated that establishing relevance (Jeffrey, 2006) can enhance not only engagement but feed into the students' learner identities, enabling them to take ownership of the learning process (Sheridan, 2011).

In the 're-contextualizing' part of the model it is important to link the deconstructed elements back to the bigger concepts. One could consider this as closing the loop. Guiding questions for students could be: 'So, how does this work?', 'What did that do?', 'And how does all of what you have just learned, explored, and played with relate to the subject knowledge?'. These questions could be asked directly or used to guide the development of activities and presentations.

Making the model effective necessitates that the learners understand where a session or intervention sits within the overall course or learning experience. Guiding questions for this might be: 'how does what we are doing in today's lecture or in today's seminar, link to the previous and the upcoming sessions?', and 'how does it fit within the overall picture of the whole semester or academic year?'. Whilst learning is a complex, personal, and socially mediated process (Garner, 2009; Claxton, Costa and Kallick, 2016), it is near to impossible to predict or understand the direction internal processes take in the individual learner. Developing the learners' meta-cognitive skills can make some of these processes more transparent and help the learners to take agency of their learning. 
Being metacognitive can be likened to being more conscious, reflective, and aware of one's progress along the learning path (Sawhney and Bansal, 2015, p.107).

Sawhney and Bansal (2015) argue for the key role educators play in supporting their learners' development of these skills. The two-step model outlined here can scaffold this development. Academic development sessions aim to support positive identity negotiations of the learners (Briggs, et al., 2012) as they are scaffolding the students' development of literacies as emancipatory practice (Sinfield, et al., 2011) by enabling the students to take agency of their learning process.

As Busseri et al (2010, p. 516) point out, first year students in particular have the need for a "structured supportive context in building personal competencies and exploring new identities". Considering these issues of transition into university, I developed an integrated approach for academic development during the first year at university. This proved an effective form of student learning development aiming to help students to become independent learners, instead of simply offering introduction sessions at the beginning of the year, or on demand sessions throughout the year. I collaborated with the heads of year, and we mapped the curriculum with the learning development tasks to offer meaningful, relevant and real-time sessions throughout the semester. This approach was taken both for the first-year master-level (of a two-year fulltime course) and first year undergraduate courses.

\section{Methodology}

I developed a 16 session module for first year undergraduate (Level 1) cohorts of Diagnostic Imaging and Radiography students, taught throughout the first academic year. I also taught seven sessions across the first year for master students in Life Sciences and Diagnostic Imaging. All learning activities were aligned with the subject specific curriculum and designed in collaboration with module leaders. For instance, sessions about reflective writing were offered two weeks before the students had to hand in their first reflective assignment to allow enough time for the students to implement their learning into the assessment. 
I obtained ethics approval to evaluate the integrated sessions, as part of my Postgraduate Certificate in Learning and Teaching in Higher Education (PGCert), in which we were tasked to take up a teaching challenge and evaluate our response to it. My challenge was to encourage students to engage with learning development sessions and improve their academic practice. Within the scope of this project and the reflection about the activities, I realised that the key principle I applied to all activities could be represented in the two-step model introduced here.

We were asked to utilize an action research approach in our project. However, due to the situation, the methodology needed to be adapted and I utilized Guerrilla Research Tactics (GRT):

GRT are influenced by and developed from a combination of participatory action research (Kindon, 2008) and unobtrusive research methods (Kellehear, 1993), to enhance social research (Caldwell, Osborne and Mewburn, 2013, p. 17).

Caldwell, Osborne and Mewburn (2013) suggest that GRTs can be applied to a wide range of academic disciplines because of the focus on engagement with communities and finding solutions. One of the challenges of the research project was finding how to access the students' perception about their experience of engaging with the learning strategies. Finding a way of improving impact and the students' understanding of this impact was also difficult. If the students understand the impact engaging with the Learning Development Centre (LDC) workshops has on their academic development, then this will enable them to take more ownership and control of the learning process. Subsequently enabling the students to become independent learners (Symonds et al., 2019; Sawhney and Bansal, 2015).

Designing learning experiences was integrally linked to data collection. For me the key points with Guerrilla Research Tactics were that they were reactionary, as I was able to build a bridge to the participants. For instance, I had planned to analyse the students' online portfolios, which evidence their professional development, as they would potentially provide a more honest and open reflection on the LDC experience than direct questioning. However, only a couple of students actually mentioned their experience with the LDC in 
their portfolios. To enable me to gain a better understanding and offer the students another feedback point, I decided to introduce another unobtrusive method for data collection. I offered the students formative feedback on an assignment, which they could volunteer for. Again, the volunteering part made reaching participants very difficult. Nevertheless, five students sent me a 500-word reflective assignment that analysed their experience with one of the sessions I offered. On one hand, this assignment provided the students with feedback on their reflective writing; on the other hand, it provided me with some understanding about the strengths and weaknesses of their learning experience.

Starting from a position of having used a research diary, standard course evaluation forms, staff interviews with module leaders from the modules I taught in, student grade marks, and classroom observations, the exploration of guerrilla research methods resulted in utilization of other methods. This included creative feedback designed by the students (Sheridan, 2013b), reflective assignments by undergraduate students about their learning experience, ePortfolios by master level students about their learning experience, and my own reflective blog.

\section{Creative learning and teaching and the two-step model}

The two examples I am using here are to exemplify how the principle of de-contextualizing and re-contextualizing can work in two entirely different settings and were part of my PGCert project. Case Study One is an example from the first-year undergraduate cohort, and Case Study Two an example from the first-year master's cohort. I chose these examples to highlight that the model can be applied in different contexts, with students at all levels.

My aim was to step away from a deficit discourse about students, the key defining characteristic of which was a culture of victim blaming, either based on individual traits and or a person's cultural background (Davis and Museus, 2019). To challenge structural inequities (Davis and Museus, 2019) in my classroom, one of the approaches I used was to translate potentially unfamiliar institutional culture, processes, or even the language that needed to be used to adhere to the performative rules and expectations within an institution. This enabled the students to take ownership and control of their learning 
process (Jeffrey, 2006), and to make these learning experiences more tangible, so they can come from a point of agency of their learning, within this new learning environment and this new culture.

The following discusses two situations based on this concept. The sessions aimed to help students to obtain ownership and control of their learning process, in establishing relevance of the learning content. Establishing this relevance was based on using the decontextualize/re-contextualize two-step model. The model is explained in more detail in the case studies.

The challenge was to move away from instructional 'this is how you do university' to creative learning and teaching approaches. I wanted to enable the students to see the value in academic development sessions for their personal development and their degree, through employing creative pedagogy. I provided a mixture of group work, creative learning strategies, online material, Socratic inquiry technique, object-based learning (Chatterjee, 2016), and storytelling techniques (Jørgensen, 2018) to contextualize learning, and thus establish relevance of learning content for the learners' academic and professional development.

\section{Case Study 1: Making feedback meaningful}

I designed the following session, aiming to enable students to understand not only their own perspective, but also that of university staff, about the feedback processes. Thus, the process aimed to improve learners' engagement with feedback and also support them to prepare their assessment by considering how their writing is being assessed. The latter in particular emerged as a significant change of perspective for the students, who used to focus solely on their own perception of their work.

Divergent thinking (Guilford, 1968) was the key aspect addressed during this activity. It literally relates to thinking in all directions and breaking through constraints and expectations imposed by social and cultural structures (Acar and Runco, 2019). It can be a useful activity for the 'de-contextualizing' part of the model. As Sun, Wang and Wegerif (2019) explain there are three cognitive strategies for divergent thinking, where 
decomposition-as in deconstructing an object, or situation into its parts-is one of these strategies. Depending on how the educator develops the 're-contextualizing' aspect of the model this can contain either one or both of the other two cognitive strategies for divergent thinking: 'association' and 'combination and adjustment' (Sun, Wang and Wegerif, 2019).

In the following examples, both of these are used during 're-contextualization' as the students were encouraged to 'construct connections between similar concepts or objects' (association) (Sun, Wang and Wegerif, 2019, p.2220) and

Two or more concepts or objects can be merged or combined into a new one. Thus, possible changes can be made to one or more parts or attributes of an object, concept or situation to generate new ideas ... (combination and adjustment) (Sun, Wang and Wegerif, 2019, p.2220).

One of the issues I observed during previous academic years was that students did not seem to be aware of the complexities of providing feedback to written assignments. While the institution had undertaken significant work in developing and implementing a successful feedback strategy - a culture change, in fact-it remained difficult for the students to take the perspective of academic staff who are marking assignments. Thus, students who attended sessions in the LDC regularly indicated confusion about feedback. They would not be able to contextualize and comprehend how their work did not fulfil the passing criteria or learning outcomes. The activity provided the students with a change of perspective and deeper understanding of the feedback process.

The structure of the feedback session was as follows. The students were put in groups of three, where each group were given one (latex-free) balloon to inflate and decorate. To pass the Balloon Academy, each balloon student had to fulfil three essential and one freestyle criteria. The essential criteria were eyes, a mouth and a bowtie, plus one freestyle item. The students had 5 minutes to decorate the balloons with a permanent marker according to these marking criteria. I then asked the groups to pass their balloons to the group to their left. Each group had a different balloon. They then had to feed back if the balloon would pass Balloon Academy based on the provided criteria (Sheridan, 2013a). 


\section{Figure 2. Balloon decorated according to marking criteria}

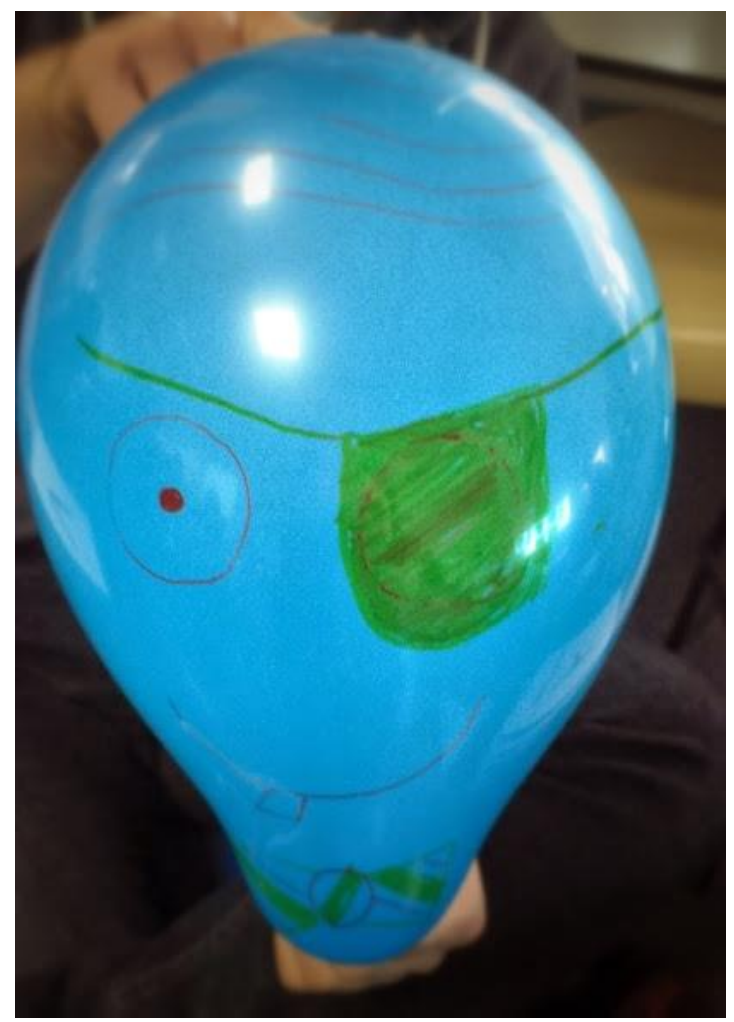

The balloon depicted above (Figure 2) was deemed to fail the Balloon Academy, because it had an eye-patch, contradicting the-initially clear, now clearly vague-instruction of 'eyes'. The judgement led to an intensive classroom discussion, in which the students immediately brought up issues around equality and diversity. The situation became an important teaching moment, addressing issues around disability, concluding this should not impact the student balloon's passing of the Balloon Academy.

The feedback exercise here seemed to remove implicit biases students hold when judging their own or others' work (Joughin, Boud and Dawson, 2019) through the decontextualization of the subject matter, in this case assessment criteria for an upcoming Diagnostic Imaging exam. Another element of the success of this activity (see evaluation below) could be that the de-contexualization of actual assessment and working with proxies (here balloons) made this exercise psychologically safe for the students. Whilst psychological safety is a complex term, the element most relevant in this situation would be that the students were not focussing on their own performance relevant to expectations (Tsuei et al., 2019) since the expectations are playful and artificial. Thus, the peer 
judgements triggered extensive discussions about inclusion, and impact of additional needs on assessment, as well as gender equality and stereotyping.

Figure 3. Some Balloon Academy candidates

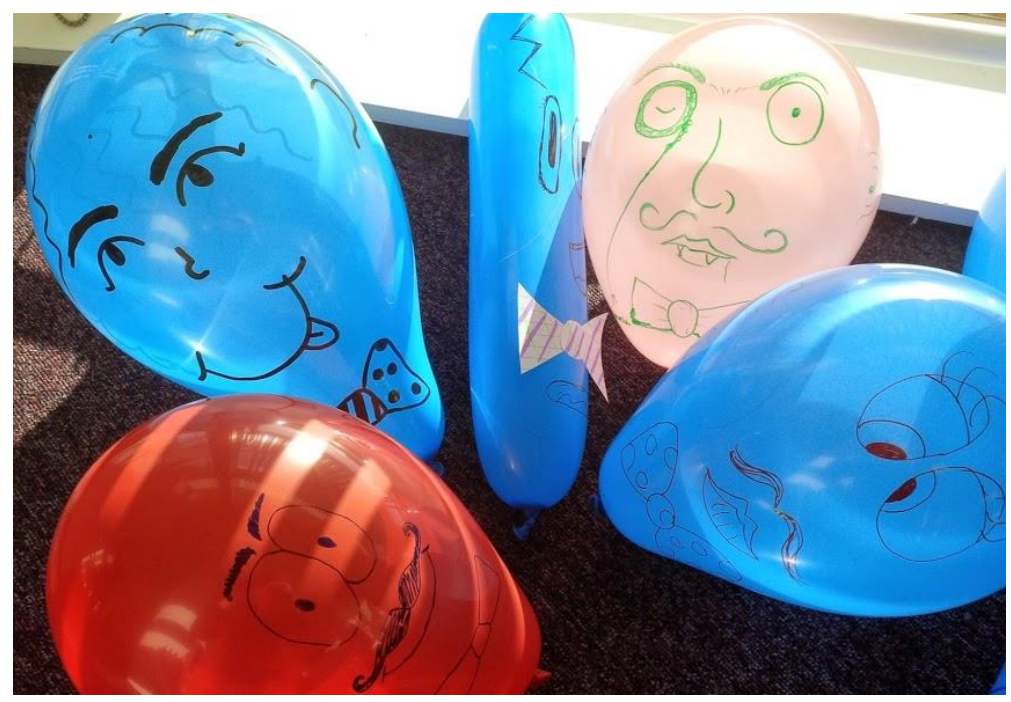

After the students had judged the respective balloons, I drew the students' attention back onto actual assessment feedback, highlighting that only three simple criteria and one freestyle item had resulted in a significant variety of outcomes. We established that despite this variety, most of the balloons had still passed the academy. The students themselves then commented on how difficult they thought it was to judge if a balloon should pass or not. This feedback was an incentive for me to explain how complex it is for academic staff marking assignments since these have more complex and numerous marking criteriatherefore re-contextualizing the learning exercise into the students' academic reality. Data from my reflective diary shows another side effect. Right after the session, the head of year led their own session with the students. In a follow-up phone call, I was asked what I had done with the students. It emerged during this call that the students, who also had to prepare portfolios for the end of the semester, had queued after my colleague's session to ask about deadlines and marking criteria for these. The portfolios were not mentioned during the feedback session, as hand-in was still several months away. My colleague asserted that the students traditionally would only inquire after the portfolio two weeks before deadline, but not a couple of months in advance. So, it appears that the strategy of de-contextualizing/re-contextualizing enabled the students to take ownership and control of making it relevant to their learning experience. Making an abstract concept more 
tangible and then bringing it back into the academic context had a wider impact on the students' understanding than I anticipated.

\section{Case Study 2: Confidence in Giving Presentations}

While the international masters students did struggle with language comprehension, most were professionals in their field, returning to university to progress their professional development (Bownes et al., 2017). These students told me they would present in front of peers and employees all the time. They were, however, nervous to present as a form of assessment within the context of their master's degree in a non-native language. One of the things I noticed when teaching non-native speaking students was that the focus was often on the translation of subject rather than the actual use and structure of language. I wanted to prevent this by designing a learning situation within which the content of the language was de-contextualized from their studies, so the students would be able to focus on the structure and flow of language and how it is used in sense making. Thus, they could potentially take ownership and control over the English language as a tool to present their ideas. Additionally, language is culture and experiencing language within the culture makes it more accessible to learners (Bonvillain, 2019). Language here, can change from a mere instrument-which is more or less bluntly used-to meaningful engagement (Bastalich, Behrend and Bloomfield, 2014). I asked the students to meet me in front of the Gallery of Modern Art in Glasgow, and if possible, bring smart phones or a camera. I asked the students to explore the temporary lan Hamilton Finlay exhibition, which was a rich mix of language and imagery. The reason for taking them to this exhibition was to enable the students to experience language differently from the restricted, narrow focus of their text-books and journal articles and to look beyond, which leads back to the three aspects of divergent thinking discussed above (Sun, Wang and Wegerif, 2019). I asked the students to take images or notes of language, words and phrases that stood out to them, in any which way (positively, negatively, or not knowing what it means). The exhibition 'had the students intrigued' as I noted in my reflections of the day.

In the research diary, I reflected about one interaction in which a student pointed to an abstract painting with dispersed blue letters jotted across it. The student stated that the 
painting did not make sense to them. So, I inquired if they had read the description next to the painting, which they had not. As the other students overheard our brief conversation this turned into a valuable teaching moment talking about the importance of contextualizing content, and the type of information that would need to be provided depending on the audience (Sheridan, 2014). We discussed what their audience would think if they used images and graphics without letting the audience or the reader know what the purpose of the images or graphics were. This was also one of the most common issues I encountered in my students' writing. They would let the imagery speak for itself without helping their audience to understand how this helps the overall narrative of their arguments.

Picking up on reflecting-in-action (Schön, 2006), and the element of surprise, taking the postgraduate students to the gallery certainly initiated strong learning incentives. During the session, engaging with different forms of text rather than the usual academic literature enabled a much stronger focus on mechanisms of language. I believe offering international students the space to explore language on their own terms, outwith the realm of subject specific literature (which only draws the focus on abilities of language comprehension, and learning subject terms) can increase their engagement with and comprehension of the language. The impact of this activity is highlighted in the following quote from a student's reflective diary.

Prior to the session, students had received a mail from the module leader to the effect that the lecture would be delivered at Glasgow Gallery of Modern Art (GOMA) as requested by the tutor. [...] A number of assumptions were made on the reason for the choice of the venue among which was the probability that since it was a Gallery of "Modern " Art, the displays were done using powerpoint. All assumptions, however, turned out to be far from the tutor's plans. [...]

The session turned out to be very helpful to the students as it provided new ideas, which if adopted properly, will ensure a successful powerpoint presentation. Random practical sessions are vital to students' understanding of some concepts. Prior to the session students would not have expected such an idea but as the session transpired, the students flowed in a relaxed atmosphere and easily made meaning of the session (taken from a student's reflective assignment, 2014). 
In a follow-up classroom session, I noted that the students had all signposted their graphics in their PowerPoint slides and did not try so hard to use the thesaurus to find sophisticated words but focussed on explaining their slides. Further, in an interview with one of the heads of year I was told that the external examiners noted a significant improvement in academic practice in the students' work, compared to previous years. My colleague related this to the integrated academic development sessions, and the impact these had on the students' practice.

Both case studies discussed here highlight how informal learning spaces can be created within a typical HEI seminar setting or are available outwith the HEI context, such as in local museums and galleries, but valuable to be utilized within the context of teaching in HEls. Approaching the pedagogical strategies from a creative learning and teaching perspective, means the creation or utilization of informal learning spaces to offer students the opportunity to take agency of the learning process (ownership and control) and understand the contexts of the learning and teaching activities (relevance) to their wider study.

\section{Evaluation}

My theoretical background is based on the understanding that we create shared meaning in negotiating with the environment and with one another which aligns with the action research approach employed for the purpose of this evaluation. The processes as described by Koshy (2005) begin with a plan, followed by action and observation, a subsequent reflection, and then begin again with a revision of the plan. Koshy's (2005) interpretation is that action research is not only 'about developing the act of knowing through observation, listening, analysing, questioning' (p. xiv) but foremost about 'being involved in constructing one's own knowledge' (Koshy, 2005, p.14). Hence, the approach is aligned with my social constructivist tendencies. However, due to the limited time available for this project, the evaluation only constitutes one iteration of the cycle described: plan, implementation, evaluation and reflection.

Interestingly, in hindsight, and this is the main reason for finally taking the decision to write this paper, the evidence collected is what I now consider the first part of a much longer 
and complex process. It provided me with the confidence to pursue my pedagogies further and translate these principles successfully into other and much wider contexts. So much so that I used these to inform the development of postgraduate courses on a Masters in Academic Practice.

Method triangulation was used within this action research project. The data collection methods were standard course evaluation forms, staff interviews with course leaders, students' grade marks and observations—in action-during the sessions. I expanded these to ask the students to design creative feedback and offered students the option to participate in reflective assignments. The last method served both as a data gathering tool, and as formative assessment for the students, to trial reflective writing, which constituted a significant part of their summative assessment. The following statement reflects my initial concern that students struggled to see the value in learning development and how this can be changed with the appropriate pedagogies:

The topic seemed uninteresting and well known that I did not expect anything revealing or useful from this session. Apparently her presentation style was very evocative - I caught myself trying to imagine myself to be engaging with the audience and showing interest and enthusiasm for the topic

In the open-ended questions and reflective assignments, the students indicated the impact of the sessions on their confidence indirectly, as the four quotes below demonstrate. Whereas the last quote demonstrates not only an overall impact on confidence, but also that the sessions offered the students specific Handlungsoptionen ${ }^{1}$ to take forward.

'all sessions were beneficial, I would have preferred to have sessions like these before university began' (taken from Student Feedback, 2014)

'helps me understand how to write essays from other modules' (taken from Student Feedback, 2014)

\footnotetext{
1 A rough translation would be course of action. However, in this context implies learning beyond the situational understanding of how to solve a problem. Handlungsoption, here implies learning that can be generalised and transferred into other situations. It means to equip the learner with a generic understanding of how to act within certain situations to solve problems, implicit to this is the development of confidence.
} 
'I had been feeling worried about the upcoming workload and responsibilities besides my revision for exams in April and May. [...] after the class ... I was happy and confident.' (taken from Student Feedback, 2014)

'During the seminar the computer unit began to malfunction. [name of tutor] dealt with the technical issues extremely well. This gives me more confidence on my own ability to deal with technological problems if any should arise.' (taken from Student Feedback, 2014)

The grade marks for the reflective assignment showed marked improvement in student grades. One student improved by 30 percent, one by 27 , nine students improved by between 10 and 20 percent points, seven students between one and eight percent. Only three out of 22 students dropped in their grade marks, one of which fell by 20 percent. To summarise, 18 out of 22 students improved their grade mark and more than half of these by 10 percent or more.

To gain more insight into the disparity between the grade marks I conducted an interview with the module leader, who indicated that the regressing marks were from students who had become known by colleagues on the programme for demonstrating a strong lack of engagement across the board, not only in my sessions. They also said that one of the students, who asked for feedback during the formative task, and who is not in this specific table, improved their paper by $40 \%$. The module leader further pointed out that all the students who said that they attended the LDC's generic workshops on top of my embedded sessions, improved by approximately $20 \%$, indicating that a combination of academic development sessions and agency of the learning process can have an impact on grade marks. Feedback from the external examiners was that the first-year cohort was the strongest academically that they had encountered, and they were impressed with the quality of academic standard of the students' work.

The results indicate a positive impact of my integrated academic development sessions on the learners. What I was not able to measure at the time, was self-efficacy. Whilst the students were directly asked about how confident they perceived they were, which was a 
standard question in the course evaluation form, a self-efficacy questionnaire would have provided a better insight into potential change of agency the learners experienced over their learning process. There was not enough qualitative data to confidently identify a pattern, although I saw a trend in improvement of confidence. However, the triangulation of all the data available provides a positive picture of these interventions.

\section{Conclusions}

Rethinking my approach to teaching academic practice sessions as a learning developer had a significant impact on the students' experience and success. Using the concepts from creative learning and teaching as a framework to design learning activities-keeping in mind the learner-built the bridge between institutional and students' expectations: aligning these different perspectives, and supporting the students in negotiating meaning within the learning environment. I chose the two case studies out of a range of activities undertaken as part of the PGCert study, because they addressed two typical problems that first year and international students face when transitioning into HEIs in the UK. Further, the activities demonstrate how the creation of informal learning spaces crosses disciplinary divides and can offer the students perspectives to enrich their learning experience. Both case studies are also a clear example for my two-step model of de-contextualizing/recontextualizing a learning object or situation.

The learning I took from the project has now influenced the development of a course for university lecturers, on a postgraduate programme where I encourage learners (who are university lecturers) to explore these creative learning processes, and the agency of their learners. I have translated the underlying principles for this project, derived from my PhD in creative learning (Sheridan, 2011), into teaching in higher education since 2010. The PGCert project enabled me to gather some evidence of the impact of these principles. There is more work to be done and more comprehensive research to undertake. The purpose of this paper was to introduce the two-step model of de-contextualizing/recontextualizing as a mechanism to design creative pedagogies and enable learners to develop their ownership and control of their learning. This not only improves the students' performativity but also improves their confidence, quality of academic work, and can positively influence transferable skills development. 


\section{References}

Acar, S. and Runco, M. A. (2019) 'Divergent thinking: New methods, recent research, and extended theory', Psychology of Aesthetics, Creativity, and the Arts 13(2), pp. 153-158. doi: 10.1037/aca0000231.

Ashwin, P., Boud, D., Coate, K., Hallett, F., Keane, E., Krause, K.-L., Leibowitz, B., MacLaren, I., McArthur, J., Tooher, M. (2015). Reflective Teaching in Higher Education. Fakenham: Bloomsbury Publishing Plc.

Bastalich, W., Behrend, M. and Bloomfield, R. (2014) 'Is non-subject based research training a "waste of time", good only for the development of professional skills? An academic literacies perspective', Teaching in Higher Education, 19(4), doi: 10.1080/13562517.2013.860106.

Biggs, J., \& Tang, C. (2011). Teaching for Quality Learning at University (4th Edition ed.). Maidenhead, Berkshire: Open University Press.

Briggs, A. J., Clark, J., \& Hall, I. (2012). Building Bridges: Understanding Student Transition to University. Quality in Higher Education, 18(1), 3-21.

Bonvillain, N. (2019) Language, Culture, and Communication : The Meaning of Messages. Available at:

https://books.google.co.uk/books?hl=en\&lr=\&id=cyyKDwAAQBAJ\&oi=fnd\&pg=PP $1 \& \mathrm{dq}=$ language + is +culture\&ots=RApf_604on\&sig=f85CQYDoRD9dKiqxXIcwMlom $\mathrm{zx} 4 \# \mathrm{~V}=$ onepage \&q=language is culture\&f=false (Accessed: 18 June 2019).

Bownes, J. et al. (2017) 'Supporting Students in the Transition to Postgraduate Taught Study in STEM Subjects', Journal of Perspectives in Applied Academic Practice, 5(2). doi: 10.14297/jpaap.v5i2.280.

Busseri, M. A., Rose-Krasnor, L., Adams, R. G., Polivy, J., Pancer, M. S., Pratt, M. W., 
Birnie-Lefcovitch, S., Wintre, M. G. (2010). A Longitudinal Study of Breadth and Intensity of Activity Involvement. Journal of Research on Adolescence, 21(2), 512 518.

Caldwell, G., Osborne, L., \& Mewburn, I. (2013) Guerrilla research tactics: alternative research methods. In J. Hamilton, \& S. Carson (Ed.), Effective Supervision of Creative Arts Research Degrees Symposium. Brisbane: Queensland University of Technology.

Chatterjee, H. J. (2016) Engaging the Senses: Object-Based Learning in Higher Education, Engaging the Senses: Object-Based Learning in Higher Education. Routledge. doi: 10.4324/9781315579641.

Claxton, G., Costa, A. L. and Kallick, B. (2016) Hard Thinking about Soft Skills. Learning for Life. 73(6)

Davis, L. P. and Museus, S. D. (2019) 'What Is Deficit Thinking? An Analysis of Conceptualizations of Deficit Thinking and Implications for Scholarly Research', NCID Currents. University of Michigan Library, 1(1). doi:

10.3998/currents.17387731.0001.110.

Garner, J. K. (2009) 'Conceptualizing the Relations Between Executive Functions and Self-Regulated Learning', The Journal of Psychology, 143(4), pp. 405-426. doi: 10.3200/JRLP.143.4.405-426.

Glasgow Caledonian University. (2014). RealWoRLDFutures @CBS. Retrieved 06 25, 2014, from http://www.gcu.ac.uk/cbsrealworldfutures/aboutemployability/: http://www.gcu.ac.uk/cbsrealworldfutures/aboutemployability/(Accessed: 25 June 2014).

Guilford, J.P., 1968. Intelligence, creativity, and their educational implications. San Diego, Calif.: R.R. Knapp

Jeffrey, B. (2006) 'Creative teaching and learning: Towards a common discourse and 
practice', Cambridge Journal of Education, 36(3), pp. 399-414. doi:

$10.1080 / 03057640600866015$.

Jørgensen, K. M. (2018) 'Spaces of performance: a storytelling approach to learning in higher education', Learning Organization. doi: 10.1108/TLO-11-2017-0104.

Joughin, G., Boud, D. and Dawson, P. (2019) 'Threats to student evaluative judgement and their management', Higher Education Research and Development. Routledge, 38(3), pp. 537-549. doi: 10.1080/07294360.2018.1544227.

Kahu, E. R., Picton, C. and Nelson, K. (2019) 'Pathways to engagement: a longitudinal study of the first-year student experience in the educational interface', Higher Education. Springer Netherlands, pp. 1-17. doi: 10.1007/s10734-019-00429-w.

Kidd, D., 2015. Becoming Mobius: The complex matter of education. Crown House Publishing.

Kolb, D. A. (2015) Experiential learning: experience as the source of learning and development. Second. Upper Saddle River, New Jersey: Pearson Education, Inc.

Koshy, V. (2005). Action Research for Improving Practice. A Practical Guide. Thousand Oaks: Paul Chapman Publishing.

Lee, V. S. (2001) 'Learning that Lasts: Integrating Learning, Development, and Performance in College and Beyond (review)', The Journal of General Education, 50(3), pp. 230-233. doi: 10.1353/jge.2001.0019.

Mckendry, S. et al. (2013) 'Researching Under-Represented Groups: How to Empower Students through Targeted Learning Development Support'. Available at: http://eprints.gla.ac.uk/151017/(Accessed: 30 March 2019).

Richards, W. et al. (2017) Recognition and belonging: engaging first generation students. Worcester. Available at: http://eprints.worc.ac.uk/5245/1/FGS Paper revision MM edit.pdf (Accessed: 28 April 2020). 
Sawhney, N. and Bansal, S. (2015) 'Metacognitive Awareness of Undergraduate Students in Relation to their Academic Achievement', The International Journal of Indian Psychology, 3(1), pp. 3135-3138.

Schön, D. A. (2006). The Reflective Practitioner. How Professionals Think in Action. Aldershot: Ashgate Publishing Limited.

Sheridan, N.. (2011). Exploring Creative Learning Processes of Refugee Children and their Peers—A Case Study (Version 1). figshare. https://doi.org/10.6084/m9.figshare.12221807.v1 (Accessed: 25 February 2020).

Sheridan, N. (2013a). Feedback Fed Back (Version 1). figshare. https://doi.org/10.6084/m9.figshare.12214373.v1 (Accessed: 25 February 2020).

Sheridan, N. (2013b). Feedback Rules! (Version 1). figshare. https://doi.org/10.6084/m9.figshare.12220394.v1 (Accessed: 25 February 2020).

Sheridan, N. (2014). Radiography, Gallery of Modern Art \& International Students (Version 1). figshare. https://doi.org/10.6084/m9.figshare.12923084.v1 (Accessed: 05 September 2020).

Sinfield, S., Holley, D., Burns, T., Hoskins, K., O'Neill, P., \& Harrington, K. (2011). Raising the Student Voice: Learning Development as Socio-political Practice. In P. Hartley, J. Hilsdon, C. Keenan, S. Sinfield, \& M. Verity, Learning Development in Higher Education (pp. 53-63). Basingstoke: Micmillan Publishers Limited.

Stebleton, M. J., Soria, K. M. and Huesman, R. L. (2014) 'First-Generation Students' Sense of Belonging, Mental Health, and Use of Counseling Services at Public Research Universities', Journal of College Counseling, 17(1), pp. 6-20. doi: 10.1002/j.2161-1882.2014.00044.x.

Sun, M., Wang, M. and Wegerif, R. (2019) 'Using computer-based cognitive mapping to improve students' divergent thinking for creativity development', British Journal of 
Educational Technology. John Wiley \& Sons, Ltd (10.1111), 50(5), pp. 2217-2233. doi: 10.1111/bjet.12825.

Symonds, J. E. et al. (2019) 'Momentary Student Engagement as a Dynamic Developmental System', PsyArXiv. doi: 10.31234/osf.io/fuy7p.

Tsuei, S. H.-T. et al. (2019) 'Exploring the Construct of Psychological Safety in Medical Education', Academic Medicine. NLM (Medline), 94(11) (Association of American Medical Colleges Learn Serve Lead), pp. S28-S35. doi: 10.1097/ACM.0000000000002897.

Zepke, N. (2017) 'Higher Education Research \& Development Student engagement in neo-liberal times: what is missing?' Higher Education Research and Development 37(2) doi: 10.1080/07294360.2017.1370440.

\section{Author details}

Nathalie Sheridan is a lecturer in academic and digital development at the University of Glasgow. Her first degree is in Erziehungswissenschaften (Learning Sciences, TU Dresden) with an MPhil (University of Glasgow) and PhD (University of Strathclyde) in education. Nathalie has worked in culture and museums education throughout her studies and has been teaching in higher education since 2006. Nathalie's focus is the translation of creative learning and teaching practices into higher education, through active pedagogies and rethinking learning spaces with the aim to improve the student experience and include disenfranchised learners and educators. 